\title{
DESAIN SISTEM INFORMASI MANAJEMEN REKAPITULASI KEHADIRAN DAN HONOR MENGAJAR DOSEN FAKULTAS TEKNIK UNIVERSITAS RIAU KEPULAUAN BATAM
}

\author{
Endang Susanti \\ Dosen Tetap Program Studi Teknik Elektro Universitas Riau Kepulauan (UNRIKA) \\ Batam
}

\begin{abstract}
Informasi merupakan sesuatu yang penting didalam suatu organisasi pendidikkan dalam pengambilan keputusan. Pemanfaatan teknologi informasi dalam organisasi pendidikan untuk mendukung kegiatan akademik, administrasi dan kemahasiswaan semakin meluas. Hal ini disebabkan karena manfaat dari teknologi informasi semakin dirasakan, baik bagi pihak manajemen maupun pihak konsumen. Pihak manajemen disuatu organisasi akan membutuhkan informasi yang akurat untuk mendukung pengambilan keputusan yang akan dilakukannya. Saat ini rekapitulasi kehadiran dan honor mengajar dosen masih direkap secara manual dengan menggunakan microsoft excel Hal ini menimbulkan beberapa permasalahan misalnya human error dan informasi yang diinginkan tidak dapat diperoleh dengan cepat dan tepat. Penelitian ini bertujuan menganalisis sistem informasi manajemen yang sedang berjalan dan mendesain sisitem informasi manajemen yang baru. Metode yang digunakan pada penelitian ini adalah metode FAST. Berdasarkan analisis kebutuhan, user dan konsumen yang terdiri dari BAAK, dosen, dekan, wakil dekan dan rektorat membutuhkan sistem informasi manajemen yang handal yang bisa diakses dengan mudah dan informasi didapat tepat waktu. Oleh karena itu perlu didesain sistem informasi manajemen rekapitulasi kehadiran dan honor mengajar dosen.
\end{abstract}

\section{PENDAHULUAN}

Suatu sistem informasi manajemen yang berbasis komputer terdiri dari manusia, perangkat keras, perangkat lunak, data, dan prosedur-prosedur organisasi yang saling berinteraksi untuk menyediakan data dan informasi yang tepat pada waktunya kepada pihak pihak di dalam maupun di luar organisasi yang berorganisasi (Parker, 1989 dalam Jogiyanto, 2005). Komputerisasi yang dikenal hanya sebagai alat bantu manusia dalam berbagai pekerjaan, kini sudah menjadi sebuah sistem yang terintegrasi dan menjadikannya sebagai alat untuk membantu dalam pembuatan suatu kebijakan manajemen (Samantrie, 2009).

Saat ini BAAK Fakultas Teknik, Sistem Informasi Manajemen untuk rekapitulasi kehadiran dan honor mengajar dosen masih secara manual, walaupun sudah menggunakan komputerisasi akan tetapi tidak merupakan sistem yang saling terintegrasi dan dalam pemasukan data administrasi hanya dinggunakan program microsoft excel. Hal ini 
menimbulkan beberapa permasalahan seperti kesalahan penginputan tanggal mengajar atau jumlah pertemuan yang dilaksanakan dosen pengampu matakuliah sehingga honor dosen yang diterima tidak sesuai yang seharusnya. Berdasarkan permasalahan tersebut timbul suatu ide untuk mendesain sistem informasi manajemen rekapitulasi kehadiran dan honor mengajar dosen.

\section{TINJAUAN PUSTAKA}

\subsection{Sistem Informasi Manajemen}

Sistem Informasi Manajemen merupakan penerapan sistem informasi didalam organsasi untuk mendukung informasi-informasi yang dibutuhkan oleh semua tingkatan manajemen. SIM (Sistem Informasi Manajemen) didefinisikan oleh George M. Scott dalam Jogianto (2005) sebagai berikut : Suatu SIM adalah kumpulan dari interaksi-interaksi sistemsistem informasi yang menyediakan informasi baik untuk kebutuhan manajerial maupun kebutuhan operasi. Sedangkan menurut Gordon B. Davis dalam Bagad (2009) Sistem Informasi Manajemen adalah sistem manusia/ mesin yang menyediakan informasi untuk mendukung operasi manajemen dan fungsi pengambilan keputusan dari suatu organisasi. Menurut Bagad (2009), manajemen didefinisikan sebagai proses perencanaan, pengorganisasian, staf dan control upaya organisasi untuk mencapai tujuan atau sasaran organisasi.

Sistem informasi mempunyai peranan yang penting didalam menyediakan informasi bagi manajemen semua tingkatan. Supaya system informasi yang dihasilkan oleh system informasi dapat mengena dan berguna bagi manajemen, maka analisis system haruslah mengetahui kebutuhan-kebutuhan informasi yang diinginkan oleh manajemen. Jogiyanto (2005). Menurut Robert K. Leitch kegiatan manajemen dihubungkan dengan tingkatannya didalam organisasi. Kegiatan manajemen tingkat atas, menengah dan bawah adalah berbeda. Kegiatan-kegitan manajemen mempengaruhi pengolahan informasi, karena informasi yang dibutuhkan berbeda 
untuk masing-masing tingkatan. Kebutuhan informasi yang berbeda ini dapat diketahui dari masing-masing kegiatan manajemen tersebut. Kegiiatan manajemen untuk masing-masing tingkatan dapat dikategorikan sebagai berikut :

1. Perencanaan strategi ( strategic planning) merupakan kegiatan manajemen tingkat atas.

2. Pengendalian manajemen ( management control) merupakan kegitan manajemen tingkat menengah

3. Pengendalian informasi ( operational control ), merupakan kegiatan manajemin tingkat bawah.

\subsection{System Development life Cycle (SDLC)}

1. SDLC (System development life cycle) atau siklus hidup pengembangan sistem adalah pengembangan sistem informasi yang berbasis komputer. Dalam penyelesaiannya membutuhkan waktu sampai berbulan-bulan bahkan bertahuntahun. Proses pengembangan sistem melewati beberapa tahapan dari mulai sistem itu direncanakan sampai sistem tersebut diterapkan. jika suatu sistem yang sudah dikembangkan menghadapi suatu masalah, maka perlu dikembangkan kembali suatu sistem untuk mengatasinnya. Hal inilah yang dinamakan siklus hidup sistem Pada System life cycle, Menurut Raymond McLeod dalam Peniarsih (2009) proses pengembangan sistem mencakup 5 (lima) tahapan, yaitu :

2. 1. Tahap Perencanaan.

3. Dalam tahap perencanaan merupakan tahapan awal yang dilakukan dalam proses perancangan suatu sistem. Pada tahap ini kegiatan yang dilakukan antara lain adalah : Menyadari masalah, mendefinisikan masalah, menentukan tujuan sistem, 
mengidentifikasi kendala-kendala sistem, membuat studi kelayakan, mempersiapkan usulan penelitian sistem, menyetujui atau menolak penelitian proyek, menetapkan mekanisme pengendalian.

4. 2. Tahap Analisis.

5. Pada saat perencanaan telah selesai, tahap selanjutnya beralih pada analisis dari sistem yang telah ada. Analisis sistem adalah penelitian atas sistem yang telah ada dengan tujuan untuk merencanakan sistem yang baru atau diperbarui. Pada tahap ini kegiatan yang dilakukan adalah : Mengumumkan penelitian sistem, mengorganisasikan tim proyek, mendefinisikan kebutuhan informasi, mendefinisikan kriteria kinerja sistem, menyiapkan usulan rancangan, menyetujui atau menolak rancangan proyek.

6. 3. Tahap Rancangan.

7. ngan memahami sistem yang ada dan persyaratan-persyaratan sistem baru, kemudian beralih pada tahap memvahas rancangan sistem baru. Rancangan sistem adalah penentuan proses dan data yang diperlukan oleh sistem baru. Ini biasanya digunakan suatu alat bantu untuk menggambarkan rancangan sistem yang akan dibuat. Alat bantu tersebut biasanya adalah Data Flow Diagram kegiatan yang dikerjakan pada tahap ini antara lain adalah : Menyiapkan rancangan sistem yang terinci, mengidentifikasikan berbagai altematif konfigurasi sistem, mengevaluasi berbagai altematif konfigurasi sistem, memilih konfigurasi yang terbaik, menyiapkan usulan penerapan, menyetujui atau menolak penerapan sistem.

8. 4. Tahap Implementasi.

9. Dalam tahap implementasi kegiatan memperoleh dan mengintegrasikan sumber daya fisik dan konseptual yang menghasilkan suatu sistem yang bekerja. Dalam kegiatan ini ada 8 (delapan) tahapan kegiatan yaitu : Merencanakan penerapan, 
mengumumkan penerapan, mendapatka sumber daya perangkat keras, mendapatkan sumber daya perangkat lunak, menyiapkan database, menyiapkan fasilitas fisik, mendidik peserta dan pemakai, masuk ke sistem yang baru.

10. Tahap Penggunaan.

11. Dalam tahapan ini mencakup 3 (tiga) kegiatan sekaligus, yaitu menggunakan sistem melakukan audit terhadap sistem yang bersangkutan dan melakukan perawatan terhadap sistem. Dalam menggunakan sistem, diharapkan pemakai menggunakan sistem sesuai dengan tujuan yang telah digariskan sebelumnya. Sedangkan pada kegiatan mengaudit sistem, dilakukan studi untuk mengetahui sampai sejauh mana sistem yang bersangkutan dapat memenuhi kriteria yang telah ditentukan sebelumnya. Kegiatan ini biasanya dilakukan berulang-ulang dengan periode tertentu. Pada kegiatan sistem selain dilakukan kegiatan yang berhubungan dengan perawatan sistem yang bersangkutan, juga dilakukan modifikasi agar sistem tetap dapat mendukung penyelesaian pekerjaan yang diperlukan. Hal tersebut dilakukan antara lain untuk :

a. Menjaga agar sistem selalu 'Up-to-date' dan sesuai dengan pekerjaan.

b. Meningkatkan kinerja karena adanya saran-saran baru yang lebih baik.

c. Memperbaiki kesalahan-kesalahan yang ada.

\section{METODE ANALISIS SISTEM INFORMASI}

Menurut Whitten, et al., (2002), metode FAST (Framework for the Applications of System Technology) adalah metode pengembangan sistem yang bersifat fleksibel dalam mendukung tipe atau proyek dan strategi yang berbeda. Metode FAST mendefinisikan tahapan untuk mengidentifikasi dan mengevaluasi permasalahan-permasalahan, kesempatankesempatan, hambatan-hambatan yang terjadi, dan kebutuhan yang diharapkan sehingga 
dapat diusulkan perbaikan-perbaikan. Tahapan pengembangan sistem dengan metode $F A S T$ adalah preliminary investigation, problem analysis, requirement analysis, decision analysis, desaian Construction dan Implementation. Akan tetapi pada penelitian ini tahapan pengembangan sistem informasi BAAK fakultas teknik hanya sampai ketahap desain sistem informasi saja.

FAST sendiri berkaitan erat dengan analisis dan desain sistem melalui cara PIECES (Performance, Information, Economics, Control, Efficiency, dan Service). PIECES membantu metode FAST pada tahap analisis masalah dan kebutuhan sistem, meliputi:

- Performance (kinerja), peningkatan terhadap kinerja sistem yang baru sehingga menjadi lebih efektif diukur dari jumlah pekerjaan yang dapat dilakukan pada saat tertentu (throughput) dan response time.

- Information (informasi), peningkatan terhadap kualitas informasi yang disajikan.

- Economics (ekonomi), peningkatan terhadap manfaat-manfaat atau keuntungan atau penurunan biaya yang terjadi.

- Control (pengendalian), peningkatan terhadap pengendalian untuk mendeteksi dan memperbaiki kesalahan derta kecurangan yang akan terjadi.

- Efficiency (efisiensi), peningkatan terhadap efisiensi operasi.

- Service (pelayanan), peningkatan terhadap pelayanan yang diberikan oleh system

\section{ANALISIS SISTEM}

\subsection{Analisis Proses Bisnis Honor Mengajar Dosen}

Proses bisnis honor mengajar dosen adalah sebagai berikut : 
1. Wakil dekan merekap jumlah pertemuan dosen berdasarkan absen mengajar setiap dosen pengampu mata kuliah untuk tiap bulannya.

2. Wakil dekan menyerahkan rekap honor dosen yang dibuat dalam program Microsoft excel diserahkan ke bagian keuangan universitas dalam bentuk hard copy, dan pihak keungan universitas akan mengajukannya ke yayasan berdasarkan jumlah honor yang telah direkap wakil dekan.

Dari proses bisnis honor mengajar dosen yang telah dijelaskan sebelumnya, terdapat kelemahan dan kelebihan dari sistem yang seperti ini kelemahannya adalah kesalahan input jumlah pertemuan dosen sedangkan kelebihannya wakil dekan dapat mengetahui jumlah kehadiran masing-masing dosen sehingga apabila terdapat jumlah pertemuan dosen yang kurang maka wakil dekan bisa menyampaikan langsung kepada dosen pengampu matakuliah untuk bisa mencukupi jumlah pertemuan.

\subsection{Analisis Masalah}

Pengelompokan permasalahan berdasarkan metode PIECES diperoleh identifikasi masalah sebagai beriikut :

1. Performance. Performansi sistem pada saat ini perlu dikembangkan untuk meningkatkan kecepatan penyediaan informasi bagi konsumen dan manajemen.

2. Information. Informasi yang disajikan belum memenuhi kebutuhan konsumen seperti membutuhkan waktu untuk menyerahkan laporan dari BAAK ke dekan, wakil dekan dan rektorat, dikarenakan sistem masih manual.

3. Economic. Jika dilakukan pengembangan sistem informasi dapat meningkatkan pelayanan kepada dosen.

4. Control. Jika dilakukan pengembangan sistem informasi maka kontrol terhadap absen dosen dan rekap honor dosen akan lebih baik. 
5. Efficiency. Jika dilakukan pengembangan sistem informasi dapat meningkatkan efesiensi dari segi biaya dan waktu.

6. Service. Dengan pengembangan sistem informasi akan meningkatkan layanan kepada dosen dengan penyediaan informasi yang cepat dan tepat.

\subsection{Analisis Kebutuhan}

Analisis kebutuhan sistem bertujuan untuk mengidentifikasi data apa dan proses apa yang dibutuhkan pada sistem baru dan menentukan kubutukan fungsional dan non fungsional dari sisitem yang baru. Kebutuhan fungsional adalah Menunjukkan fasilitas apa yang dibutuhkan serta aktivitas apa saja yang terjadi dalam sistem baru sedangkan kebutuhan non fungsional adalah hak akses untuk menggunakan sistem informasi yang baru.

A. Analisis Kebutuhan Data

Data Rekap Honor Dosen : nama dosen, nomor induk karyawan dosen, nomor induk nasional dosen, tanggal dan hari perkuliahan, nama matakuliah, sks, semester, program studi,total pertemuan, jumlah honor

B. Analisis Kebutuhan Proses

\section{Proses Rekap Honor Dosen}

a. Data : nama dosen, nomor induk karyawan dosen, nomor induk nasional dosen, tanggal dan hari perkuliahan, nama matakuliah, sks, semester, program studi,total pertemuan, jumlah honor

b. Menambah data : nama dosen, nomor induk karyawan dosen, nomor induk nasional dosen, tanggal dan hari perkuliahan, nama matakuliah, sks, semester, program studi,total pertemuan, jumlah honor

c. Mengkoreksi data : nama dosen, nomor induk karyawan dosen, nomor induk nasional dosen, tanggal dan hari perkuliahan, nama matakuliah, sks, semester, program studi,total pertemuan, jumlah honor 
d. Menghapus data : nama dosen, nomor induk karyawan dosen, nomor induk nasional dosen, tanggal dan hari perkuliahan, nama matakuliah, sks, semester, program studi,total pertemuan, jumlah honor

\section{Analisis Kebutuhan Antarmuka}

Antarmuka rekapitulasi kehadiran dosen, antarmuka ini dibutuhkan untuk merekap honor dosen setiap bulannya, dengan adanya antarmuka ini memudahkan pihak BAAK universitas untuk melihat kehadiran dosen setiap matakuliah dan dengan antarmuka ini juga dosen bisa melihat berapa jumlah honor yang diperoleh untuk setiap bulannya.

\section{DATA FLOW DIAGRAM (DFD)}

\subsection{DFD Data Master Dosen}

Gambar 1 adalah DFD data master dosen, dosen akan melakukan entry data secara online melalui form isisan biodata dosen dilayar online, data-data yang di entry dosen adalah nama dosen, nomor induk karyawan dosen, no induk dosen nasional, jenjang pendidikkan dosen, tempat tanggal lahir dosen, riwayat jabatan fungsional dosen dan bidang keahlian. Data-data ini akan diolah oleh sistem sehingga menghasilkan informasi biodata dosen dan akan tersimpan pada database sistem sebagai data master dosen..

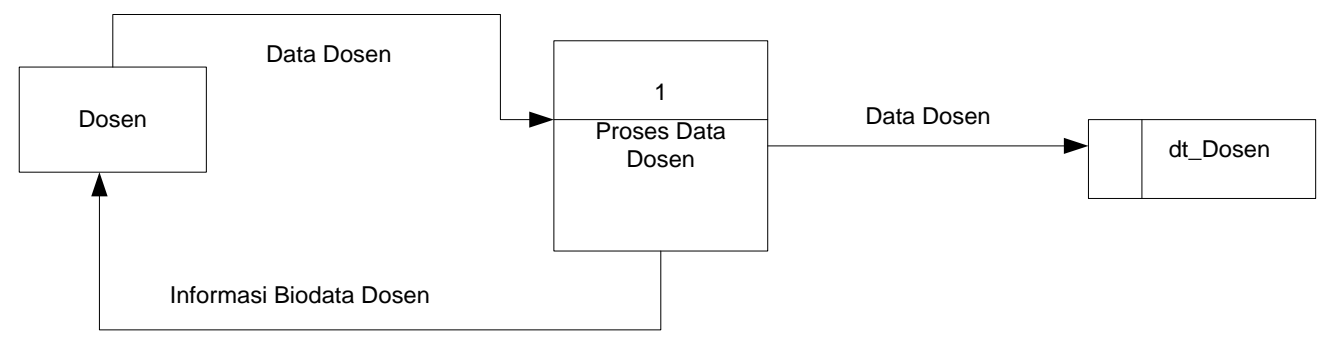

\section{Gambar 1 Gambar DFD Data Master Dosen}

\subsection{DFD Level 0 Rekap Honor Dosen}

Gambar 2 adalah gambar DFD level 0 Rekap Honor Dosen, input untuk proses rekap honor dosen terdiri dari data kehadiran dosen dan tariff honor dosen untuk setiap kali pertemuan atau setiap kali kehadiran dosen. Dosen akan mengisi form kehadirn dosen secara 
online untuk setiap kali pertemuan perkuliahan, kehadiran dosen akan diproses sistem dan menghasilkan output data kehadiran yang kemudian akan menjadi input pada rekap honor dosen. Wakil rektor II bagian kepegawaian dan keuangan akan menginput tarif honor dosen untuk setiap kali kehadiran dosen, tarif di tentukan berdasarkan jenjang pendidikkan dosen dan sks untuk setiap matakuliah, tarif akan diproses pada sistem dan menghasilkan output data tarif, data tarif akan menjadi input pada proses rekap honor dosen, sistem akan memproses jumlah kehadiran dan tarif, sehingga menghasilkan output rekap honor dosen untuk setiap bulannya.

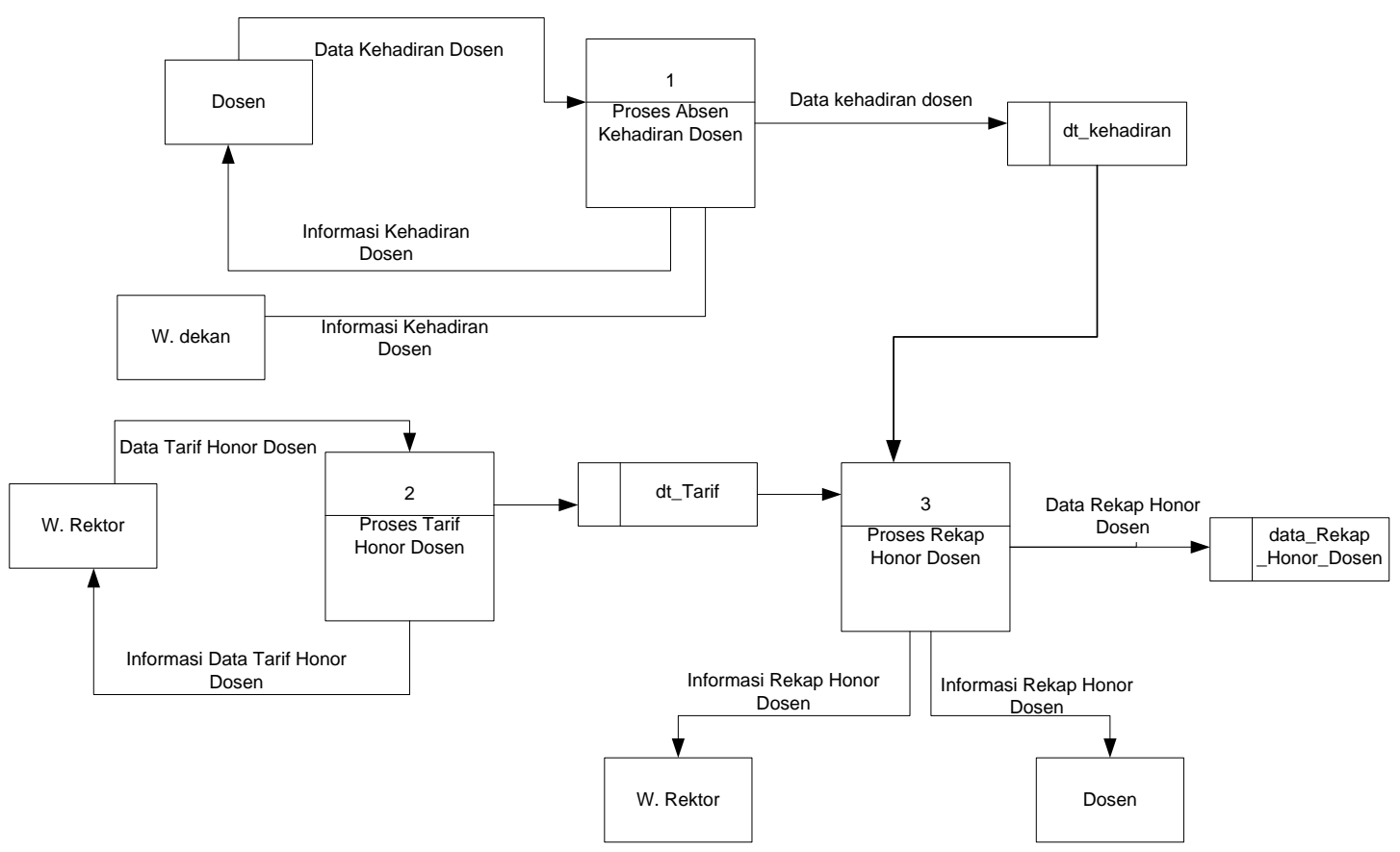

Gambar 2 Gambar DFD Level 0 Rekap Honor Dosen 


\section{ENTITY RELATIONSHIP DIAGRAM (ERD)}

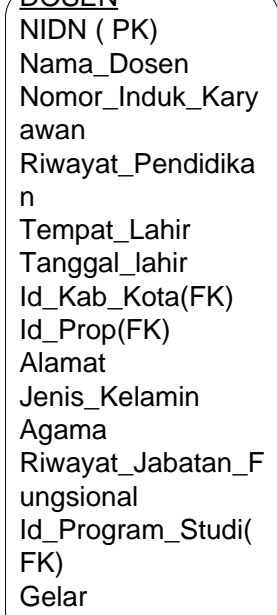

\section{KURIKULUM}

Kode Matakuliah (FK) Nama_Matakuliah SKS

Semester

Matakuliah_Prasyarat Progdi

Nomor_Revisi_Kuriku lum

MAHASISWA
NPM (FK)
Nama_Mahasiswa
Tempat_Tanggal_Lahir
Jenis_Sekolah_Menen
gah
Alamat_Sekolah_Mene
ngah
Alamat_Orang_Tua
Alamat_Surat_Menyura
t
Nomor_Handphone

\section{Gambar 3 Entity Relationship Diagram}

\section{DESAIN ANTAR MUKA}




\subsection{Desain Antarmuka Kehadiran Dosen}

Gambar 4 adalah gambar login kehadiran dosen secara online, pada saat dosen hadir untuk melakukan proses belajar dengan mahasiswa maka sebelumnya dosen melakukan login kehadiran dosen pada sistem, gambar 5 adalah gambar tampilan kehadiran dosen.

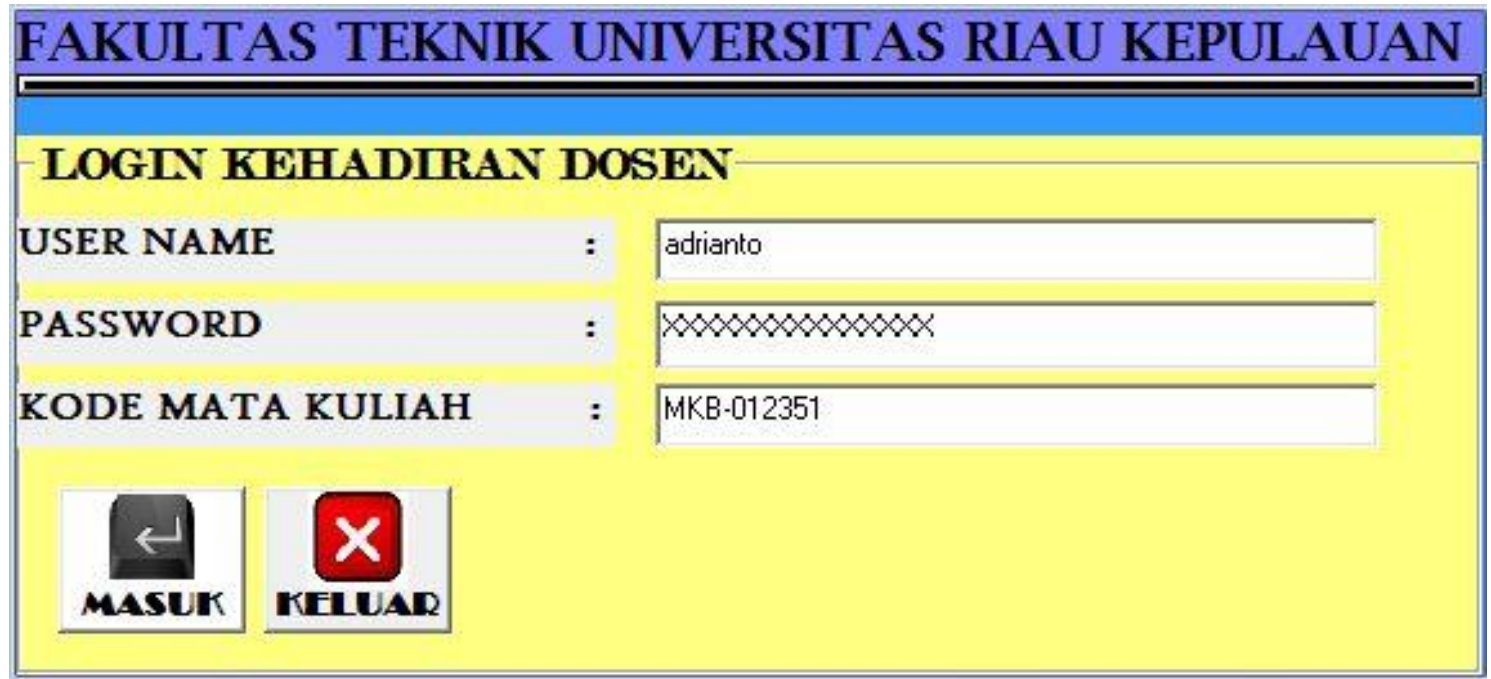

Gambar 4 Gambar Login Kehadiran Dosen Secara Online

\begin{tabular}{|c|c|c|c|c|}
\hline No. & NAMA DOSEN & Kode MK & NAMA MK & PERTEMUAN 1 \\
\hline 1 & Tri Tarwiyani, 5.Fil, M.Phil & MPB-011201 & PANCASILA & $\square$ \\
\hline 2 & Adrianto, S.Pd & MKB-012351 & FISIKA 1 & $\square$ \\
\hline 3 & Rumani Dyah C, S.Si & MKK-301305 & KALKULUS 1 & $\square$ \\
\hline
\end{tabular}

dosen akan otomatis terbentuk ketika dosen melakukan login pada kehadiran dosen pada saat proses belajar mengajar dengan mahasiswa, sistem akan memproses menjadi tampilan rekap honor dosen sesuai dengan formulanya

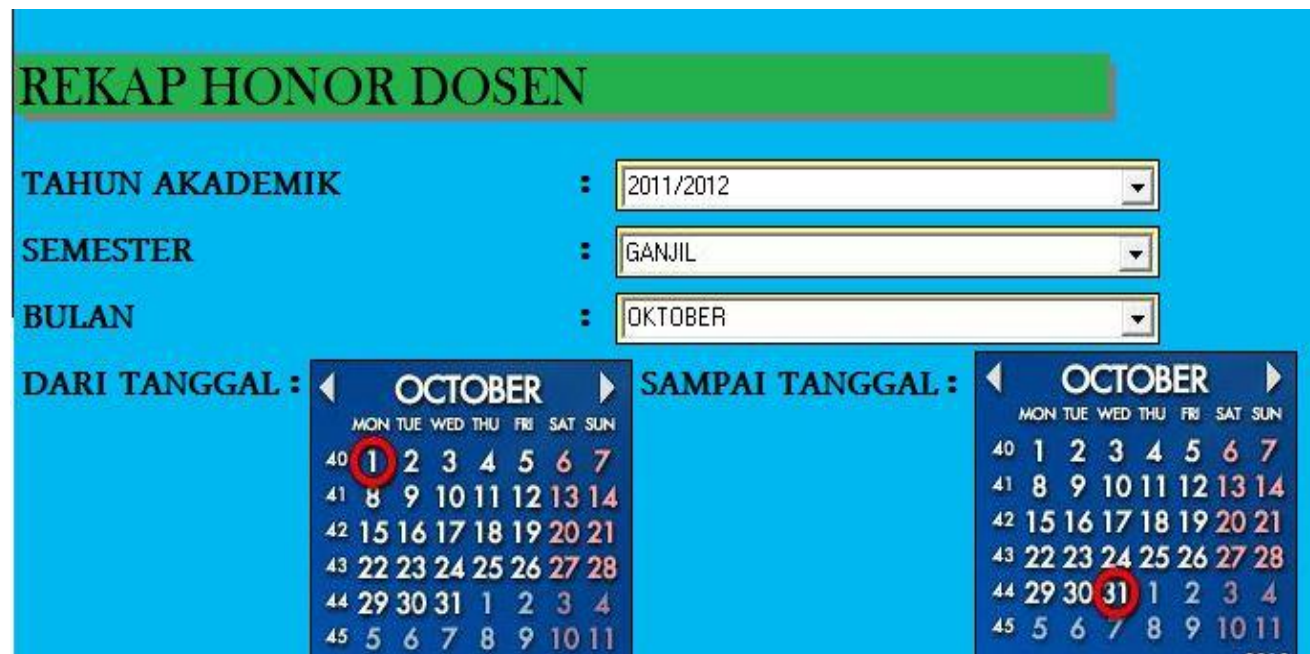




\section{Gambar 6 Tampilan Kehadiran Dosen}

\section{DAFTAR PUSTAKA}

1. Bagad, V. S, 2009, Manajement Information System, India: Technical Publication Pune, fourth revisied edition, 2009

2. Dengen, N dan Dyna, M., 2009. Sistem Informasi Akademik berbasis Web SMP Negeri 4 Samarinda, Jurnal Informatika Mulawarman Vol 4 (2).

3. Fajar, N, 2009, Diagram Arus Data (Data Flow Diagrma/DFD), e book, Multi Global Informasi, 2009

4. Gupta, P, 2005, Structured System Analysis And Design, India: Firewall Media, 2005

5. Hanani, A, 2008, Rancang Bangun Sistem Informasi Akademik Online Universitas Islam Negeri Malang, Skripsi, Teknik Informatia, UIN Malang, 2008

6. Jogiyanto, 1989, Analisis \& Desain. Yogyakarta: Andi Yogyakarta, edisi ketiga, 2005

7. Kumorotomo, W dan Margono, 2009, Sistem Informasi Manajemen dalam Organisasi-Organisasai Publik, Yogyakarta : Gadjah Mada University Press, Cetakan Keenam, 2009

8. Peniarsih, 2009., Analisa dan Perancangan system Informasi Akademik Universitas Suryadarma Jakarta, 13 Juni 2011, http//www. Ppeniarsih @ yahoo.co.id 
9. Singh, S. K, 2009, Database System Concepts Design And Application, India: Dorling Kindersley, 2009 